\title{
Advances in Experimental Medicine and Biology
}

\section{Volume 863}

\section{Editorial Board}

Irun R. Cohen, The Weizmann Institute of Science, Rehovot, Israel N. S. Abel Lajtha, Kline Institute for Psychiatric Research, Orangeburg, NY, USA

John D. Lambris, University of Pennsylvania, Philadelphia, PA, USA Rodolfo Paoletti, University of Milan, Milan, Italy 
More information about this series at http://www.springer.com/series/5584 
Neville Vassallo

Editor

Natural Compounds as Therapeutic Agents for Amyloidogenic Diseases

黛 Springer 


\section{Editor}

Neville Vassallo

Department of Physiology

and Biochemistry

University of Malta

Msida, Malta

\section{Library of Congress Control Number: 2015942700}

\section{Springer Cham Heidelberg New York Dordrecht London}

(C) Springer International Publishing Switzerland 2015

This work is subject to copyright. All rights are reserved by the Publisher, whether the whole or part of the material is concerned, specifically the rights of translation, reprinting, reuse of illustrations, recitation, broadcasting, reproduction on microfilms or in any other physical way, and transmission or information storage and retrieval, electronic adaptation, computer software, or by similar or dissimilar methodology now known or hereafter developed.

The use of general descriptive names, registered names, trademarks, service marks, etc. in this publication does not imply, even in the absence of a specific statement, that such names are exempt from the relevant protective laws and regulations and therefore free for general use.

The publisher, the authors and the editors are safe to assume that the advice and information in this book are believed to be true and accurate at the date of publication. Neither the publisher nor the authors or the editors give a warranty, express or implied, with respect to the material contained herein or for any errors or omissions that may have been made.

\section{Printed on acid-free paper}

Springer International Publishing AG Switzerland is part of Springer Science+Business Media (www.springer.com) 


\section{Preface}

A large group of human diseases are characterised by the deposition of insoluble proteinaceous lesions, termed amyloid. The underlying pathogenic process in these disorders involves the misfolding and self-assembly of native monomeric proteins into toxic, multimeric aggregates. Indeed, "protein misfolding" is one of the most researched topics in cell biology and subcellular biochemistry in recent years. To date, more than 20 amyloidogenic proteins have been identified, including amyloid-beta and tau in Alzheimer's disease, alpha-synuclein in Parkinson's disease, huntigtin in Huntington's disease, superoxide dismutase in amyotrophic lateral sclerosis, prion protein in Creutzfeldt-Jakob disease and islet amyloid polypeptide in type 2 diabetes mellitus. Collectively, these disorders inflict an enormous economical burden on societies, whilst being devastating at a personal level. It is therefore of paramount importance to understand their origin and learn how to treat, or prevent, them. At present, there are no approved therapies that target amyloid formation directly, but a wealth of experimental and epidemiological evidence now indicates that various naturally derived compounds have beneficial antiamyloid effects.

This book volume was written with the aim of disseminating the stateof-the-art and most recent knowledge of the field, highlighting the most promising nutra-therapeutics derived from natural compounds or extracts. The focus is mainly on Alzheimer's disease and related dementias; however, Parkinson's disease and other forms of cerebral amyloidosis are also discussed. Evidence is presented based upon published studies that have undergone rigorous scientific peer review. Researches include a combination of in vitro (biophysics, biochemistry, molecular and cellular biology), in vivo (fruit fly, transgenic mice and rats) and epidemiological (human) studies, so as to provide the reader with a holistic scientific approach. Among the therapeutic agents that are discussed in detail, we find Mediterranean diet and olive oil polyphenols, teas and catechins, natural phenolic compounds and bioflavonoids. Given the recent surge of public interest in herbal medicines, a chapter is devoted to evidence-based traditional Chinese medicine in brain ageing. Individual chapters are written by established scientists in their relevant fields; sufficient background is given in each chapter by way of introduction to the non-expert reader. Hence, this book should be of interest to a wide audience, including academia, various health professionals, the nutraceutical industry and undergraduate students reading for pharmaceutical, medical, biology and chemistry degrees. 
I conclude by stating that, on a personal level, the most noble goal of this book is that with our collective contributions to scientific progress, we aim to provide hope for the future and hope for the many people suffering from as yet incurable amyloid diseases. This book is, after all, dedicated to them.

Msida, Malta

Neville Vassallo 


\section{Contents}

1 Olive Oil Phenols as Promising Multi-targeting Agents Against Alzheimer's Disease

Stefania Rigacci

2 Alzheimer's Disease, Drosophila melanogaster and Polyphenols

Marlene Jimenez-Del-Rio and Carlos Velez-Pardo

3 Biflavonoids as Potential Small Molecule Therapeutics for Alzheimer's Disease

Arjun Thapa and Eva Y. Chi

4 Natural Phenolic Compounds as Therapeutic and Preventive Agents for Cerebral Amyloidosis

Masahito Yamada, Kenjiro Ono, Tsuyoshi Hamaguchi, and Moeko Noguchi-Shinohara

5 Brain Food for Alzheimer-Free Ageing: Focus on Herbal Medicines.

Helmut M. Hügel

6 Tea Polyphenols in Parkinson's Disease

Mario Caruana and Neville Vassallo

7 The Effect of (-)-Epigallo-catechin-(3)-gallate on Amyloidogenic Proteins Suggests a Common Mechanism . . 139 Kathrin Andrich and Jan Bieschke

Index 